\title{
On the Role of Non-metallic Inclusions in the Nucleation of Acicular Ferrite in Steels
}

\author{
D. S. SARMA, A. V. KARASEV and P. G. JÖNSSON \\ Department of Materials Science and Engineering, Royal Institute of Technology (KTH), SE-100 44 Stockholm, Sweden.
}

(Received on February 5, 2009; accepted on April 20, 2009)

\begin{abstract}
The effects of non-metallic inclusions in nucleating acicular ferrite in steels during cooling from a weld or cooling from an austenitic temperature are reviewed. The influence of the acicular ferrite (AF) structure on mechanical properties of steels such as strength and toughness is briefly mentioned. The different factors affecting the formation of acicular ferrite, such as the soluble content of alloying elements in steel, cooling rate from austenitizing temperature, austenite grain size and inclusion characteristics in steel, are discussed. The mechanisms of acicular ferrite formation on non-metallic inclusions, such as reduction of interfacial energy, mismatch strain between the inclusion and ferrite/austenite, thermal strains at the inclusions and changes in matrix composition near the inclusions are also discussed. Finally, the effects of inclusion characteristics, such as size, number and composition are described and their effectiveness in nucleating acicular ferrite is discussed.
\end{abstract}

KEY WORDS: non-metallic inclusions, intragranular acicular ferrite formation, strength and toughness, steel.

\section{Introduction}

Nonmetallic inclusions in steel are generally considered to be harmful to its properties as it is well established that the ductility, toughness, fatigue strength and corrosion resistance are adversely affected by them. ${ }^{1-4)}$ However, it is well known that sulfide inclusions improve machinability though oxides are very detrimental to it. It is also well known for several decades that killed steels are fine grained compared to rimmed steels and this effect was attributed to AlN inclusions. ${ }^{5)}$ However, it is of course very difficult to get ultra-fine grain sizes by this method. Thanks to the prolonged and detailed studies on weldments in the fusion zone to improve its toughness, considerable knowledge has been acquired on the role of inclusions in controlling the grain size of steels. This has basically been obtained by developing the acicular ferrite (AF) structures and several reviews have earlier been written on this subject. ${ }^{6-13)}$

Considerable information is now gathered on the role of individual impurity elements ( $\mathrm{S}, \mathrm{O}$, and $\mathrm{N}$ mainly) and their interactions with alloying elements such as $\mathrm{Mn}, \mathrm{Al}, \mathrm{Si}, \mathrm{Ti}$, and $\mathrm{Ce}$ in obtaining fine microstructures. There is now considerable enthusiasm to extend these principles to the development of wrought steels with better mechanical properties through development of fine-grained AF structures. The present paper reviews the useful role of nonmetallic inclusions in steel in promoting AF.

\section{Effect of Acicular Ferrite on Mechanical Properties of Steels}

It is well known that the different microstructural constituents formed during cooling and austenite-ferrite transformation of mild and low-alloy steel weld metals are influenced by the cooling rate, metal chemical composition and some other factors. In practice, each austenite grain after austenite-ferrite transformation includes two or more various microstructural constituents. The commonly found microstructures of ferrite in different steels are usually classified as any of the following shapes ${ }^{6,10,14,15)}$ :

grain boundary allotriomorphs ferrite (GBA or GBF),

intragranular polygonal ferrite (PF or IPF),

Widmanstätten ferrite side plates (WF or FSP),

intragranular acicular ferrite (AF or IAF),

upper and lower bainite (B),

martensite $(\mathrm{M})$.

The typical photographs of various morphology structures are shown in Fig. 1. Furthermore, the temperature ranges for formation of various morphologies are presented in Fig. 2 as a function of carbon content in a $\mathrm{Fe}-\mathrm{Fe}_{3} \mathrm{C}$ diagram. $^{14)}$

The acicular ferrite (AF) is generally expected to form in the bainite range of temperatures. Various authors ${ }^{8,15,18-22)}$ have reported that the AF is generated at different temperature ranges in the vicinity of $650-440^{\circ} \mathrm{C}$ depending on the exact chemical compositions and cooling rate of steels. The acicular ferrite arises when the low-carbon steel is cooled from the austenitic state at a rapid rate, to suppress the formation of GBA, WF and massive ferrite. ${ }^{6-13)}$ It is also a 

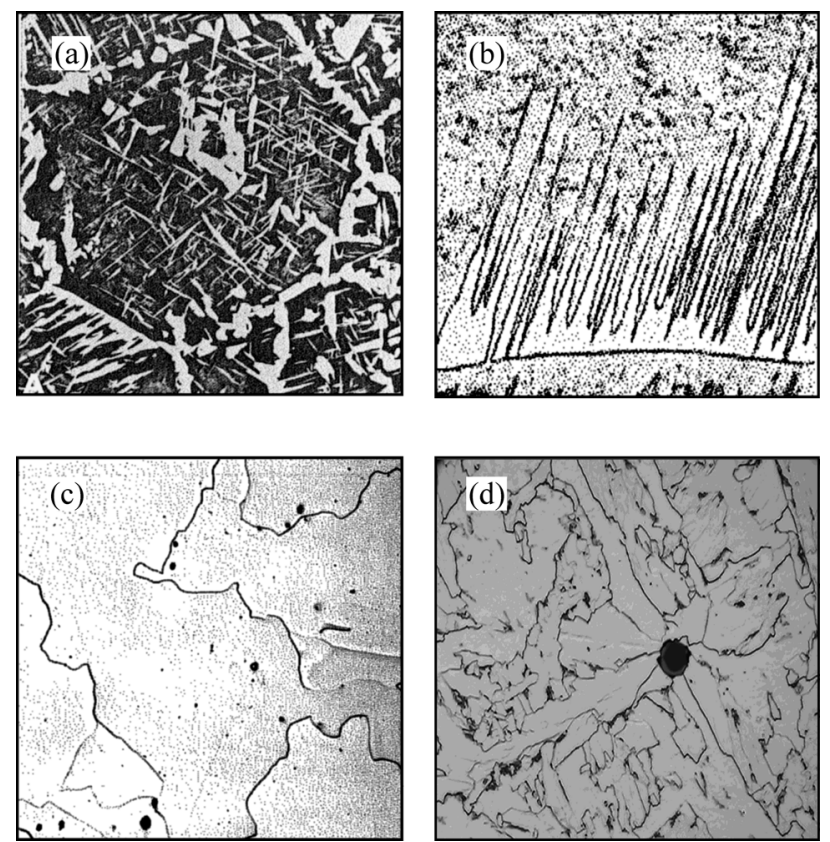

Fig. 1. Typical photographs of various morphology structures. (a) Grain boundary allotriomorphs and (b) Widmanstätten ferrite side plates in isothermally transformed $0.29 \%$ C steel, ASM. $^{15)}$ (c) Massive ferrite structure with irregular grain boundaries in $\mathrm{Fe}-0.002 \% \mathrm{C}$ alloy quenched from $1000^{\circ} \mathrm{C}^{16)}$ (d) Intragranular acicular ferrite nucleated at an inclusion. ${ }^{17)}$

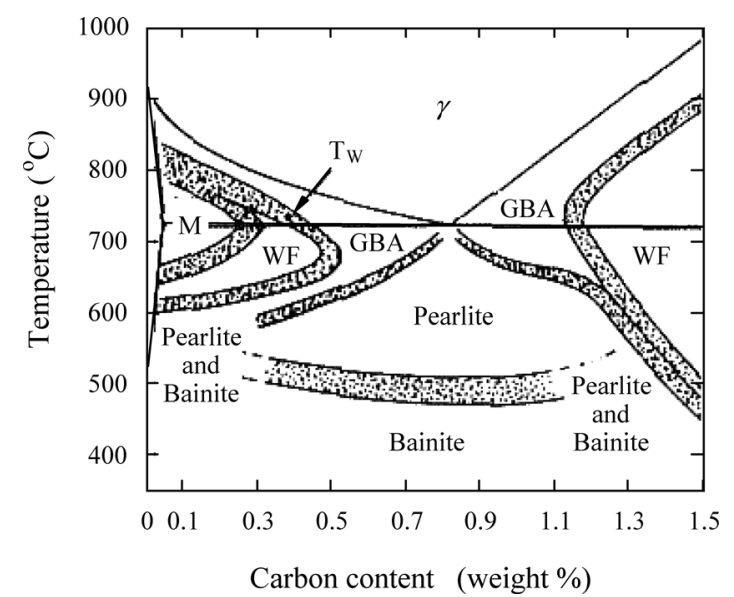

Fig. 2. $\mathrm{Fe}-\mathrm{Fe}_{3} \mathrm{C}$ diagram of temperature-composition regions with various ferrite morphologies. GBA, grain boundary allotriomorphs; WF, Widmanstätten side plates; M, massive ferrite. ${ }^{14)}$

common constituent in several welded low-carbon steels. The rate of transformation is much higher than the formation of GBA or WF, but is lower than that for martensitic transformation. The transformation temperature generally overlaps with that of a bainitic transformation. However, unlike bainite, it nucleates intragranulary at inclusion boundaries, as shown in Fig. 1(d). The acicular ferrite, as the name implies, is not equiaxed but has the length of about 5 times the width. Moreover, the latter is usually about $1 \mu \mathrm{m}$. In addition, they have much higher dislocation densities $\left(10^{6}-10^{8} \mathrm{~mm}^{-2}\right)$ than GBA or WF but lower than that of martensite $\left(\sim 10^{10} \mathrm{~mm}^{-2}\right)$.

The schematic illustration of a propagation path for a cleavage crack in steel grains with different microstructure

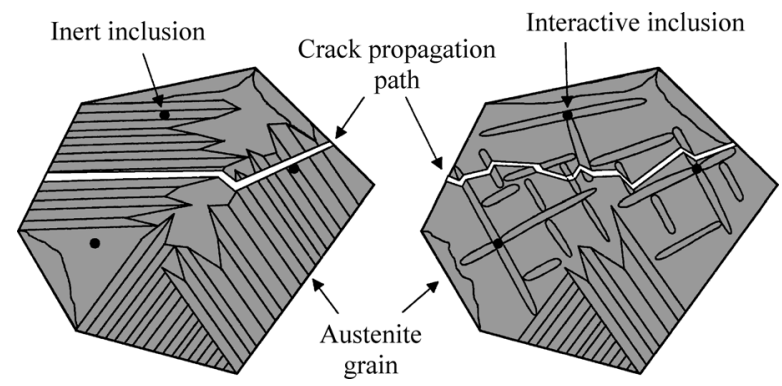

Fig. 3. Schematic illustration of propagation path for cleavage crack in the steel grains with ferrite side plate (Widmanstätten ferrite or upper bainite) and intragranular acicular ferrite. ${ }^{17)}$

is shown in Fig. 3. The path is given as a function of the spatial orientation of the ferrite side plate and intragranular ferrite laths. ${ }^{17)}$ As follows from this figures, the ferrite side plate (such as Widmanstätten ferrite or upper bainite) provides preferential crack-propagation paths in grains. This is due to that the ferrite side plates nucleate at grain boundaries as parallel plates with the same crystallographic orientation. Therefore, the toughness of steels decreases with an increasing amount of these structures. Alternatively, the acicular ferrite laths nucleate intragranularly at the surface of inclusions. Then, they have a chaotic crystallographic orientation, resulting in a retardation of the propagation path for a cleavage crack in the metal. Therefore, it can be expected that the steel toughness increases with an increasing amount of acicular ferrite in the steel.

The testing results of mechanical properties in fused weld metal and heat-affected zone (HAZ) obtained in several studies show that the strength and toughness of metal are determined in many cases by the proportion of acicular ferrite in the microstructure. The effect of the proportion of the AF content on the yield strength and Charpy "V" toughness in $\mathrm{C}-\mathrm{Mn}-\mathrm{Nb}$ steel welds, which was given by Farrar and Harrison ${ }^{8)}$ as summary analysis of several authors data, is shown in Fig. 4. It is apparent that the yield strength increases and fracture-appearance transition-temperature decreases significantly with an increased proportion of acicular ferrite in microstructures (from 45 to $90 \%$ in all studies).

The results of other authors ${ }^{10,17,21,23-28)}$ also show the improvements of mechanical properties in weld metal and HAZ with an increased proportion of acicular ferrite in the microstructure. For instance, Garland and Kirkwood ${ }^{24,25)}$ found that additions of $\mathrm{Mo}-\mathrm{Nb}$ or $\mathrm{Mo}-\mathrm{Ti}$ improved the toughness due to AF formation in the welds of C-Mn steel. Thewlis $^{21)}$ reported that even in wrought (thermo-mechanically treated) steels as well as in HAZ of welds, fine cerium sulphide inclusions initiated the formation of acicular ferrite in steel and imparted very good toughness. Similarly, Peng et al. ${ }^{26)}$ found that in submerged arc welds of X-70 line-pipe steel $(0.087 \% \mathrm{C}, 1.5 \% \mathrm{Mn}$ and $0.014 \% \mathrm{Ti})$, TiN inclusions nucleated AF which resulted in a high toughness. Even in fire resistant steels, Ohkita and Horii ${ }^{10)}$ found that AF steels are better than steels with ferrite-pearlite structures with respect to strength and toughness at high temperatures. Also, it has been found that the AF structures can result in superior stress-corrosion-cracking resistance, ${ }^{29)}$ which is needed in line-pipe steel grades. In addi- 


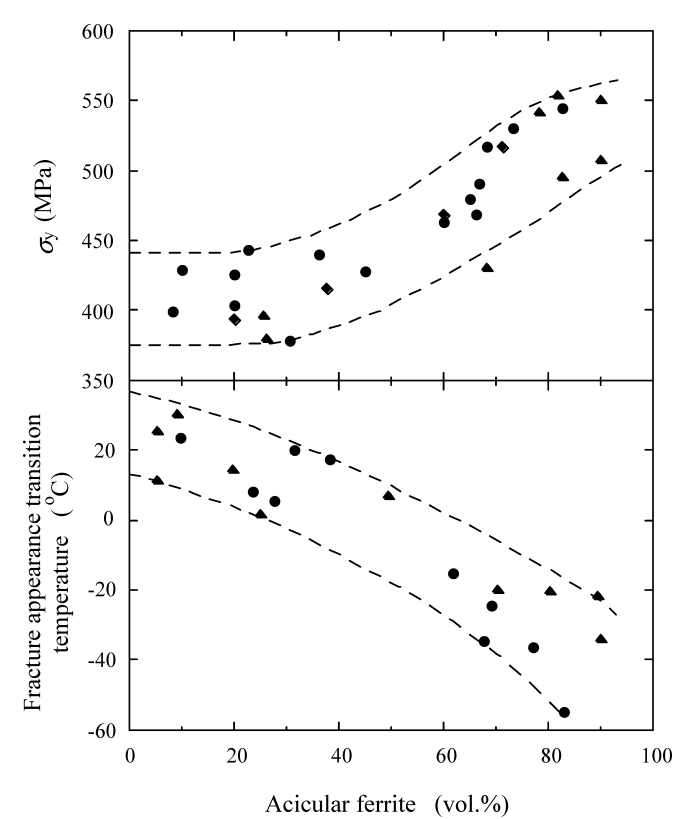

Fig. 4. Variation of yield strength, $\sigma_{\mathrm{y}}$, and fracture appearance transition temperature with the proportion of acicular ferrite for $\mathrm{C}-\mathrm{Mn}-\mathrm{Nb}$ weld metals. ${ }^{8}$ )

tion, Fairchild et al. ${ }^{27,28)}$ optimized the fracture toughness of line-pipe steel welds by engineering the inclusions to develop a microstructure of AF interspersed in martensite (AFIM). This resulted in a high yield strength, a good fracture toughness (even at $-40^{\circ} \mathrm{C}$ ), and a good hydrogen cracking susceptibility. Therefore, the analysis of factors and mechanisms influencing the formation of acicular ferrite is very important for control of a metal microstructure. Furthermore, for the improvement of the mechanical properties such as strength and toughness of steel grades during the final part of the steel production.

\section{Factors Affecting the Formation of Acicular Ferrite}

As mentioned above, the presence of acicular ferrite in a microstructure can improve the strength and toughness of the weld metal and/or the heat-affected zone (HAZ). Therefore, various authors have discussed the effect of different factors such as i) chemical composition of steel, ii) cooling rate in the temperature range 800 to $500^{\circ} \mathrm{C}$, iii) size of austenite grains, and iv) inclusion parameters on the formation of intragranular acicular ferrite in metal. These factors will be briefly discussed below. However, in real practice it is difficult to determine the influence of each factor separately.

\subsection{Content of Soluble Alloying Elements}

The chemical composition of metal is a major factor controlling the final microstructure and mechanical properties of steel. In real practice, the steels contain often many (from 3 to 7) alloying elements. In this case, it is very difficult (not feasible) to analyse the effect of several elements on the formation of AF in steel. Based on the results of various authors, ${ }^{6,8,10)}$ the role of different alloying elements on the ferrite nucleation can be generally be summarized as follows:

- a changing of the $\gamma-\alpha$ transformation temperature and as a result increasing $(\mathrm{Mn}, \mathrm{Ni}, \mathrm{C}$ and some other elements) ${ }^{30)}$ or decreasing (Al, Si, V, Cr, Mo, Ti and some other elements) the austenite zone,

- a reduction of grain boundary energy, due to the segregation of solute elements such as B. ${ }^{31,32)}$ These results in an increase of the energy barrier and a decrease of the possibility for ferrite nucleation on the surface of grain boundaries,

- a precipitation of inclusion particles favorable for nucleation of ferrite at the inclusion surface during the $\gamma-\alpha$ transformation.

The most effective soluble elements influencing the formation of acicular ferrite are $\mathrm{C}, \mathrm{Mn}$ and $\mathrm{Si}$. As shown in Fig. 2, the carbon content in steel has a powerful effect on the transformation temperature and the formation of various ferrite morphologies. The typical level of carbon content in a weld metal must be in the range of 0.05 to $0.15 \%$ to control the carbide formation and the solidification structure. $^{6,8,33,34)}$ For C-Mn SMA multilayer steel welds, a Mn content of about $1.5 \%$ is considered to be optimum to decrease the transformation-temperature. Furthermore, to increase the amount of acicular ferrite, especially at reasonably high cooling rates from the austenitic temperature. ${ }^{35)}$

An optimum content of solute alloying elements such as $\mathrm{Al}, \mathrm{Nb}, \mathrm{Mo}$ and $\mathrm{Ni}$ can also increase the possibility of $\mathrm{AF}$ nucleation and the ratio of acicular ferrite in the final microstructure. For instance, a $\mathrm{Ni}$ content of approximately $3 \%$ in a low-carbon steel is considered optimum to decrease the transformation-temperature and to increase the amount of acicular ferrite, especially at reasonably high cooling rates from the austenitising temperature. ${ }^{6}$ Similarly, Tuliani et $a .^{36}{ }^{36}$ concluded that $1 \% \mathrm{Ni}$ additions to $\mathrm{C}-\mathrm{Mn}$ welds were sufficient to promote AF formation, which in turn improved the toughness. Also, Bose-Filho et $a l .{ }^{37)}$ found that in Ti-killed steels, only the addition of $\mathrm{Ni}$, Mo or $\mathrm{Cr}$ increased the hardenability to give AF structures in combination with bainite and low carbon martensite. In addition, Garland and Kirkwood ${ }^{24,25)}$ found that additions of Mo-Ti-B to C-Mn steel welds resulted in AF formation. Thus, overall it has been found that it is very important to carefully control the composition of the steel by having optimum amounts of carbon and alloying elements with respect to the microstructure.

\subsection{Cooling Rate of Steel}

The cooling rate of steel initiated from the austenitic state is also an important factor to consider with respect to the formation of acicular ferrite. In the case of welding, this is often given by the cooling time, $\Delta t_{8 / 5}$. More specifically, this is the time it takes to cool from 800 to $500^{\circ} \mathrm{C}$, under which the austenite transforms to ferrite. The microstructure which is formed during the austenite-ferrite transformation depends directly on $\Delta t_{8 / 5}$. Furthermore, it changes i) usually from martensite (M) and/or bainite (B) at low $\Delta t_{8 / 5}$, ii) to grain boundary ferrite (GBF) with ferrite side plates (FSP) and/or intragranular acicular ferrite (IAF) at medium $\Delta t_{8 / 5}$, and iii) to mainly intra-granular polygonal ferrite (IPF) and/or pearlite (P) at high $\Delta t_{8 / 5} \cdot{ }^{23,30,38,39)}$ The typical continuous-cooling-transformation (CCT) diagrams obtained for medium carbon steels containing $0.025 \% \mathrm{Ti}$ are shown in Fig. 5 as a function of the cooling rate. Also, 


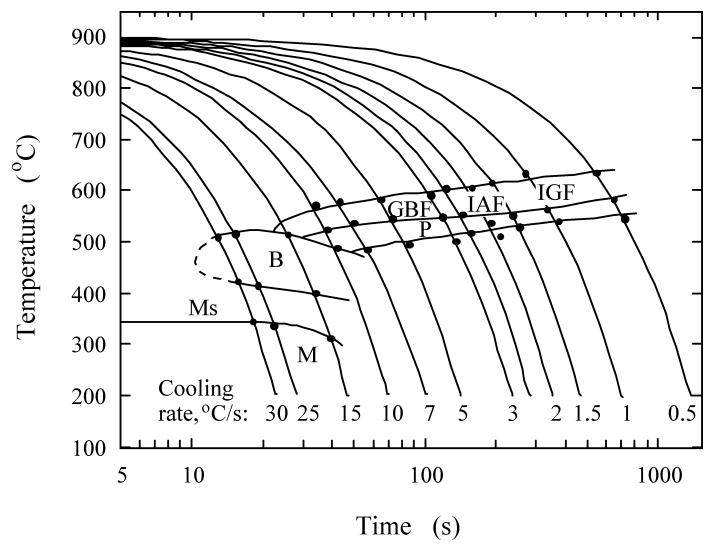

Fig. 5. Effect of cooling rate on microstructure formation of medium carbon steel with $0.025 \%$ Ti after austenitizing at $900^{\circ} \mathrm{C}$ for $10 \mathrm{~min}^{23)}$

Yang et al. ${ }^{23)}$ found that for medium-carbon steel grades, with a $0.025 \% \mathrm{Ti}$ content, the cooling rate in the range from 0.5 to $2.5^{\circ} \mathrm{C} / \mathrm{s}$ corresponds to a zone of intragranular ferrite (IGF) formation which consist of IAF and IPF.

It should be pointed out that the optimal cooling rate for the formation of intragranular acicular ferrite depends on the chemical composition of the steel grade. For example, a large volume fraction of IGF in medium-carbon steels, lowcarbon steels and medium-carbon vanadium-steels were observed at cooling rates of $10,{ }^{40)} 5,{ }^{41,42)}$ and $0.1^{43)}{ }^{\circ} \mathrm{C} / \mathrm{s}$, respectively.

\subsection{Austenite Grain Size}

The interphase surface is required for the heterogeneous nucleation of a new phase to take place during the austenite-ferrite transformation. Therefore, the possibility for formation of GBF and FSP, on the surface of grain boundaries and for the intragranular nucleation of AF on the surface of inclusions, depends directly on the total surface areas of grain boundaries, $A_{\mathrm{GB}}$, and intragranular inclusion particles, $A_{\mathrm{P}}$, in metal, respectively.

It may safely be suggested that the possibility of IAF nucleation on inclusions and consequently the volume fraction of acicular ferrite in metal microstructure increases with an increasing ratio between the surface areas of inclusion particles and grain boundaries, $A_{\mathrm{P}} / A_{\mathrm{GB}}$. According to this, it is desirable to increase the surface area of intragranular inclusions and to decrease the area of grain boundaries. Therefore, an increased grain size limits the grain boundary area available for nucleation of GBF and FSP. This fact promotes the formation of AF. For example, the effect of austenite grain size on acicular ferrite formation in weld metal is shown in Fig. 6. ${ }^{44)}$ It can be seen that the fraction of acicular ferrite increases with an increased austenite grain size.

It must be pointed out that the growth of the austenite grain size is strongly limited by the inclusions present in the metal. ${ }^{45)}$ Therefore, in real practice, a further increase of grain size for augmentation of the $A_{\mathrm{P}} / A_{\mathrm{GB}}$ value is possible only if the number of inclusions in metal is decreased. This results in a decreased $A_{\mathrm{P}} / A_{\mathrm{GB}}$ value and reduces the possibility for intragranular nucleation of acicular ferrite on inclusions. According to this, it can be expected that the volume fraction of $\mathrm{AF}$ in the microstructure and consequently

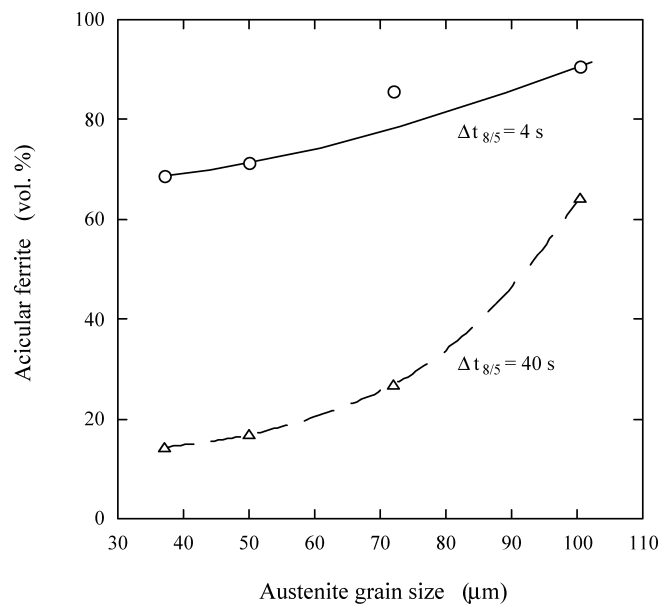

Fig. 6. Effect of austenite grain size and cooling rate on acicular ferrite formation. ${ }^{44)}$

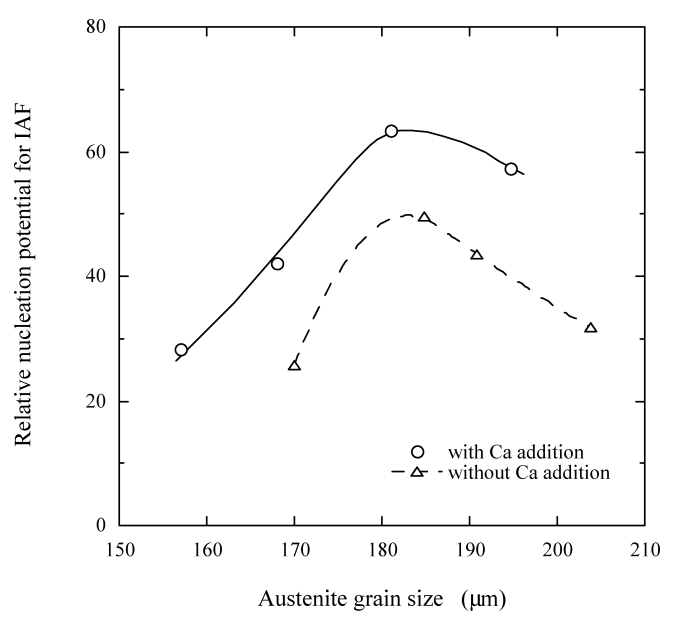

Fig. 7. Effect of austenite grain size on relative nucleation potential for intragranular acicular ferrite in Ti-killed steel without and with additions of $\mathrm{Ca}^{46}$

the steel properties begin to be reduced with a further increased grain size to more than a required value. Therefore, the relationships between the volume fraction of acicular ferrite and austenite grain size tend to follow a C-type curve. This C-type relationship was obtained experimentally by Lee and $\operatorname{Pan}^{46)}$ for Ti-killed steels without and with additions of $\mathrm{Ca}$. Figure 7 shows the effect of the mean austenite grain size in metal on a relative nucleation potential for intragranular acicular ferrite, which can be estimated by Lee's approach. ${ }^{47)}$ It can be seen that the value of the nucleation potential increases with an increased mean size of the austenite grains. Thereafter, it reaches a maximum at a $180-185 \mu \mathrm{m}$ size, before it decreases with a further increased grain size. This tendency corresponds well with results obtained by Thewlis. ${ }^{48)}$ However, it should be pointed out that the optimal size of austenite grains for formation of AF in metal can be different for various steel grades, as shown in Fig. 7. The figure presents data for steels with and without additions of $\mathrm{Ca}$. The difference in optimal size is due to the effects of different chemical composition and cooling rate of steels. Therefore, acicular ferrite formation cannot be explained solely by changing of the austenite grain size without consideration of the steel composition and the inclusion characteristics. 


\subsection{Inclusion Particles}

It is well known that the non-metallic inclusions in the steel matrix to a large degree influence the heterogeneous nucleation of acicular ferrite on inclusions in the weld metal and heat-affected zone (HAZ). The analysis of main mechanisms and effect of different inclusion characteristics (such as size, number and chemical composition) on the formation of $\mathrm{AF}$ structure are discussed in the following sections.

\section{Mechanisms of Acicular Ferrite Nucleation}

In the open literature, the following mechanisms have been suggested to cause nucleation of acicular ferrite at inclusions:

- a reduction in the interfacial energy for simple heterogeneous nucleation on a surface of inclusions, ${ }^{49-54)}$

- an epitaxial nucleation on the inclusions, which have a good coherency with ferrite, ${ }^{55-57)}$

- a nucleation arising from the thermal strains at the inclusions, which is associated with the different thermal expansion coefficients of the inclusions and steel matrix, ${ }^{58,59)}$

- a nucleation arising from solute depletion of elements in the matrix near inclusions. ${ }^{10,12,46,60-65)}$

It should be pointed out that it is, in many cases, difficult to decide which mechanism that is most important for formation of acicular ferrite. Instead, it is believed that these mechanisms often work together to promote the intragranular nucleation on inclusions.

\subsection{Reduction in Interfacial Energy}

Ricks et $a l^{49)}$ stated that an inclusion will provide an inert, incoherent and non-deformable interface that provides suitable nucleation sites for acicular ferrite just because the interfacial energy is lowered due to nucleation. The energy needed for heterogeneous nucleation of ferrite at inclusion surfaces is higher than that at grain boundaries. However, it is much less than that for homogeneous nucleation, as illustrated in Fig. 8. It can be seen that the larger inclusions $(\sim 0.5 \mu \mathrm{m}$ radius $)$ are more energetically favor-

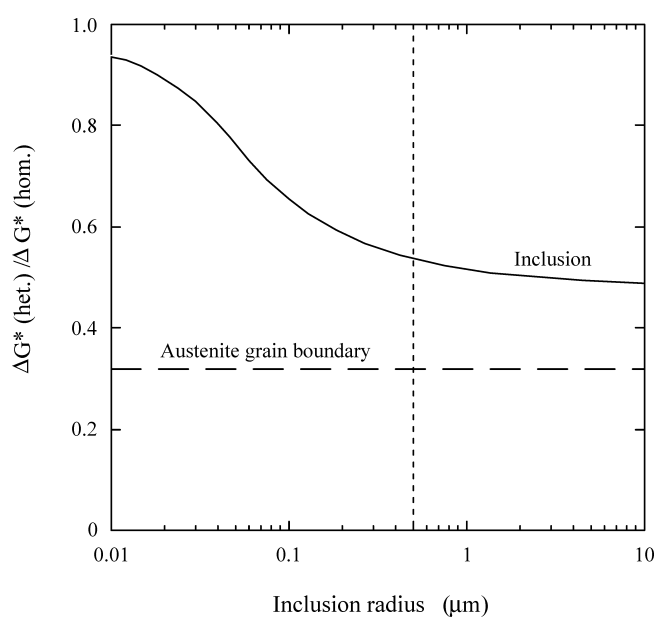

Fig. 8. Effect of particle radius on energy barrier to heterogeneous nucleation of ferrite at inclusions, $\Delta G_{\text {(het.) }}^{*}$, normalized with respect to homogeneous nucleation barrier, $\Delta G_{(\text {(hom.) }}^{*}{ }^{49)}$ able than the smaller ones, due to that the decrease in curvature is larger for the smaller ones. According to this proposition, even the chemical composition of the inclusion is not important. ${ }^{49)}$

Grong et $a .^{50)}$ also suggested that the reduction of the energy barrier is the primary cause of nucleation. In addition, Zhang and Farrar, ${ }^{51)}$ Lee et al. ${ }^{52)}$ and Furuhara et $a l{ }^{53,54)}$ reported that the surfaces of inclusions acted as inert substrates, with the ability to reduce the free energy barrier to nucleation.

Consequently, it may be concluded that though the inclusion provides the external surface needed for nucleation, it is not as effective as the grain boundary. The free energy for heterogeneous nucleation is always higher at the inclusion surface than at grain boundaries as shown in Fig. 8. The energy for nucleation is of course much lower than for homogeneous nucleation. Therefore, the size and number of inclusions as centers of heterogeneous nucleation of AF are very important for improvements of the metal microstructure.

\subsection{Lattice Mismatch Strain}

This lattice mismatch concept proposed by Bramfitt ${ }^{55}$ has drawn maximum attention. He suggested that the mismatch strain between the inclusion and ferrite/austenite should be low for nucleation to occur. For this, the simple crystallographic planes of ferrite (or austenite) and inclusion should be parallel and the two phases should have a simple crystallographic orientation relationships. The upper and lower diagrams of Fig. 9 show such matchings for TiC and WC with ferrite, respectively. More specifically, it is shown that the disregistry is low for $\mathrm{TiC}$ and high for WC. ${ }^{55)}$ Thus, TiC and not WC, has the potential to nucleate AF.

The mismatch strain, $\delta$, can be calculated from the following equation:

$$
\delta_{(h k l)_{\mathrm{n}}}^{(h k l)_{\mathrm{s}}}=\sum_{i=1}^{3}\left(\frac{\left|\left(d_{[w w w]_{\mathrm{s}}^{i}} \cos \theta\right)-d_{[w v w]_{\mathrm{n}}^{i}}\right|}{3 \times d_{[w w w]_{\mathrm{n}}^{i}}}\right) \times 100
$$
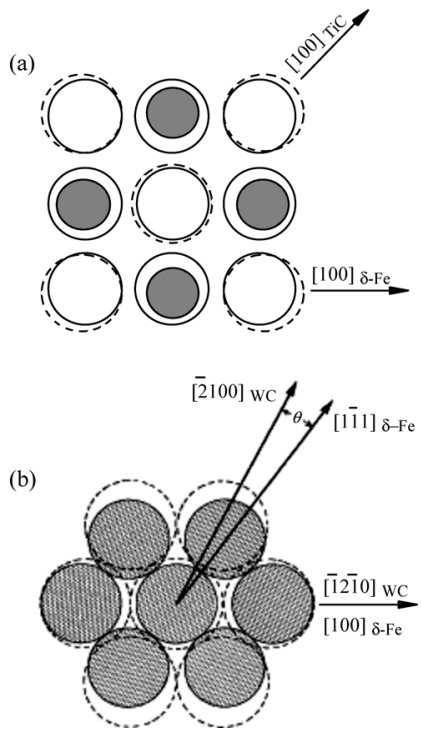

Fig. 9. Crystallographic relationship at interface between carbide (a) (100) TiC or (b) (0001) WC and (100) $\delta$ iron. ${ }^{55}$ 
Table 1. Planar disregistry and their characteristic supercooling values along with their effectiveness as nucleants for six compounds. ${ }^{55)}$

\begin{tabular}{cccc}
\hline $\begin{array}{c}\text { Compound } \\
\text { added }\end{array}$ & $\begin{array}{c}\text { Planar } \\
\text { disregistry }\end{array}$ & $\begin{array}{c}\text { Characteristic } \\
\text { supercooling, } \Delta \mathrm{Tc}, \\
{ }^{\circ} \mathrm{F}\end{array}$ & $\begin{array}{c}\text { Relative } \\
\text { effectiveness }\end{array}$ \\
\hline $\mathrm{TiN}$ & 3.9 & 3.1 & very effective \\
$\mathrm{TiC}$ & 5.9 & 3.3 & very effective \\
$\mathrm{SiC}$ & 6.0 & 7.5 & moderately effective \\
$\mathrm{ZrN}$ & 11.2 & 12.6 & moderately effective \\
$\mathrm{ZrC}$ & 14.4 & 24.5 & least effective \\
$\mathrm{WC}$ & 29.4 & 29.0 & least effective \\
\hline
\end{tabular}

where $(h k l)_{\mathrm{s}}$ and $(h k l)_{\mathrm{n}}$ are the low-index planes of the substrate and in the nucleated solid, respectively. Furthermore, $[u v w]_{\mathrm{s}}$ and $[u v w]_{\mathrm{n}}$ are the low-index directions in $(h k l)_{\mathrm{s}}$ and $(h k l)_{\mathrm{n}}$, respectively. In addition, the parameters $d_{[u v w]_{\mathrm{s}}^{i}}$ and $d_{[u w w]_{\mathrm{n}}^{i}}$ are the interatomic spacing along $[u v w]_{\mathrm{S}}$ and $[u v w]_{\mathrm{n}}$, respectively.

The calculated planar disregistries and their characteristic supercooling values along with their effectiveness as nucleants for six compounds are shown in Table 1. ${ }^{55)}$ It can be seen that the values of lattice disregistry were very small for TiN and $\mathrm{TiC}$ (3.9 and 5.9\%, respectively). The compounds $\mathrm{ZrC}$ and $\mathrm{WC}$ have much higher lattice disregistries and more characteristic supercooling values. Therefore, they were least effective as nucleants. Moreover, $\mathrm{SiC}$ and $\mathrm{ZrN}$ are in between these two extreme cases.

Thus, according to Bramfitt, ${ }^{55)}$ it is essential for inclusions to have simple crystallographic orientation relationships that result in low mismatch strains with ferrite. These inclusions should also cause a high supercooling of the melt (low characteristic supercooling temperatures) to act as nucleation sites. In addition, it is important to have an epitaxial relationship between the inclusion surface and nucleating ferrite than between ferrite and parent austenite.

However, results obtained by Gregg and Bhadeshia ${ }^{66)}$ in steel inoculation experiments with TiN and other inclusions show that the lattice matching is not the dominant requirement for nucleation of acicular ferrite.

\subsection{Thermal Strains at the Inclusions}

The thermal coefficient of expansion (in this case, the contraction) of the inclusion is different from that of the steel matrix. Hence, cooling from a high temperature will induce tessellated stresses in the material near inclusions. These stresses are a function of the following parameters: i) the elastic modulus of the steel, $E$, ii) the temperature difference over which the steel is cooled, $\Delta T$, and iii) the difference in thermal expansion coefficients between the steel matrix and the inclusion, $\Delta \alpha$. Since these stresses cause strain in the steel matrix, it is expected that the higher the stress, the higher will the strain be and the easier will the nucleation of acicular ferrite be. ${ }^{6}$ )

The values of thermal expansion coefficient, $\alpha$, reported in several studies ${ }^{58,67,68)}$ are shown in Fig. 10. Data are provided for different inclusions in the steel with respect to the austenite matrix. Furthermore, all inclusions in this figure are arranged in order of increasing $\Delta \alpha$ value and assumed possibility of acicular ferrite nucleation on inclusions. It

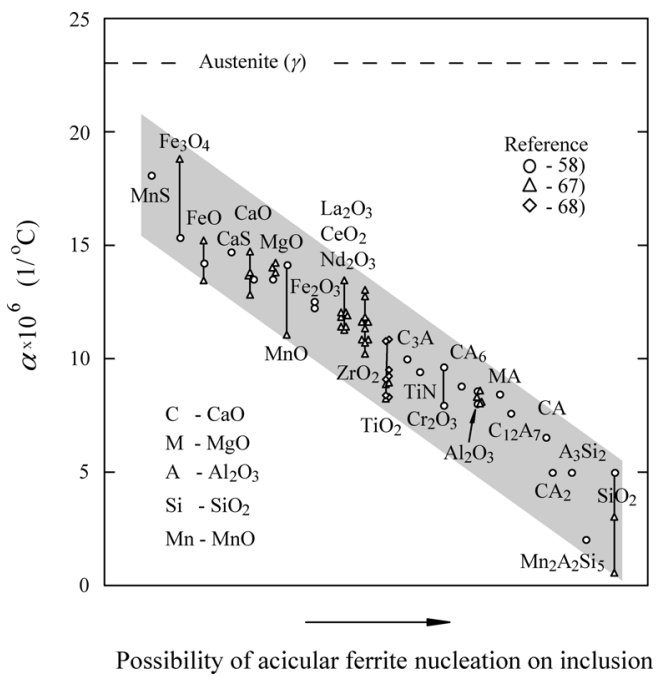

Fig. 10. Variation of thermal expansion coefficient, $\alpha$, for different inclusions in steel with respect to the austenite matrix.

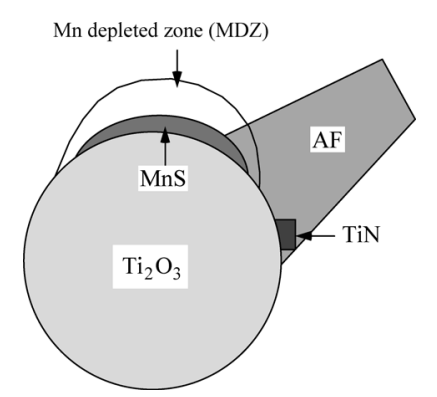

Fig. 11. Schematic illustration of heterogeneous nucleation for acicular ferrite on a surface of $\mathrm{Ti}_{2} \mathrm{O}_{3}$ inclusion with a Mn-depleted zone near a MnS inclusion. ${ }^{61)}$

can be seen that the difference in thermal expansion coefficients between the austenite and $\mathrm{MnS}$ or Fe oxides is lower in comparison with other inclusions. The tessellated stresses induced during contraction in the metal matrix near these inclusions are very small. Therefore, the $\mathrm{MnS}$ and Feoxides are not effective for AF nucleation due to the small induced tessellated stresses in the metal near these inclusions. The possibility of acicular ferrite nucleation on inclusions increases with an increased $\Delta \alpha$ value. Thus, Mn-Alor Al-silicates are very effective from this point of view.

\subsection{Depletion of Mn Content near Inclusions}

During the last $10-15$ years many studies ${ }^{10,12,46,60-65)}$ have discussed the effect of a Mn-depleted zone (MDZ) near inclusions on the acicular ferrite formation. It is well known that an increased $\mathrm{Mn}$ content promotes the enlargment of the austenite zone in steel. Therefore, a decreased Mn concentration in the metal near precipitated MnS inclusions reduces the austenite zone and contributes to the nucleation of ferrite in a MDZ. According to this model, MnS inclusions can be active sites for nucleation, because their formation depletes $\mathrm{Mn}$ in the matrix around the inclusion. This, in turn, increases the transformation-temperature to promote the acicular ferrite nucleation. The schematic illustration of acicular ferrite, which is nucleated on a surface of inclusion in Mn-depletion zone, is shown in Fig. 11.

Mabuchi et $a l .{ }^{60)}$ have studied the HAZ of welded joints 


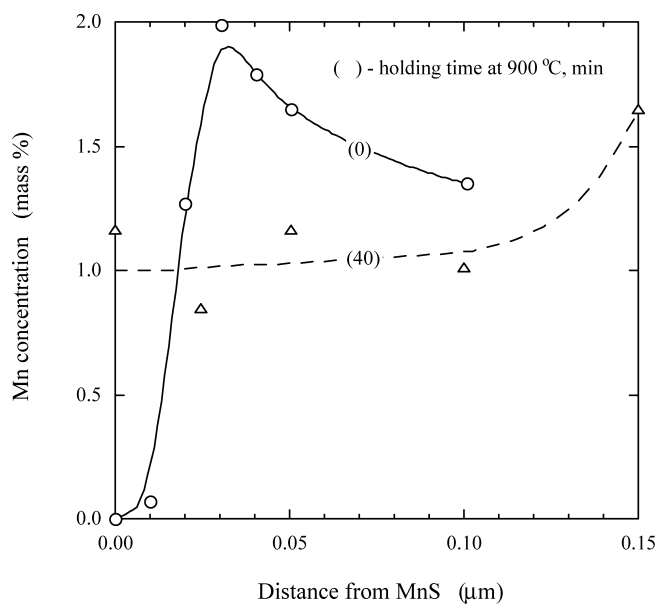

Fig. 12. Actual interfacial profiles of Mn concentration in steel matrix after MnS precipitation as function of holding time at $900^{\circ} \mathrm{C}^{60)}$

by Field-Emission Transmission Electron Microscopy (FETEM) coupled with EDS. They found that the Mn depletion in as-quenched steels decrease considerably with distance from a newly precipitated $\mathrm{MnS}$, as shown in Fig. 12. However, the Mn-depleted zone near a MnS inclusion decreases significantly with an increased holding time of metal before the $\gamma-\alpha$ transformation. Furthermore, it also happens at a decreased cooling rate of steel, due to the Mn diffusion and homogenization of the Mn concentration. As shown in Fig. 12 , the MDZ is not observed near MnS inclusions after the metal has been kept for $40 \mathrm{~min}$ at $900^{\circ} \mathrm{C}$.

The effect of Mn concentration in the MDZ on the energy barrier to ferrite nucleation at the surface of inclusions with different sizes is shown in Fig. 13. ${ }^{64)}$ It can be seen that the activation energy for heterogeneous nucleation of ferrite decreases with a decreased Mn content in the MDZ. As a result, the nucleation of ferrite is more favorable on inclusion surfaces with diameters larger than $1 \mu \mathrm{m}$ at very low contents (about $0 \%$ ) of Mn than on surfaces of austenite grain boundaries.

According to the discussion in Sec. 4.3, the potential of particles completely covered by $\mathrm{MnS}$ in the nucleation of intragranular ferrite is significantly lower than that of Tioxide inclusions. This is due to the low difference in thermal expansion coefficients between the austenite and MnS. The increase of a precipitated MnS layer on the surface of Ti-oxide inclusions above a definite value is liable to decrease the possibility of intragranular acicular ferrite (IAF) formation on inclusions. Therefore, it can be assumed that the $\mathrm{AF}$ proportion in a steel microstructure has a maximum value at the optimum content of $\mathrm{S}$ in steel. The effect of $\mathrm{S}$ content in steel on the volume fraction of IAF in HAZ is shown in Fig. 14. ${ }^{46)}$ Maximum values of the volume fraction for intragranular acicular ferrite in the microstructure were obtained for 48 and 102 ppm sulfur contents in steel with and without $\mathrm{Ca}$ additions, respectively. It should be pointed out that the optimum range of $\mathrm{S}$ content for a maximum AF proportion in metal is different for various steel grades, as shown for steels without and with $\mathrm{Ca}$ additions in Fig. 14.

Ohkita et al. ${ }^{10)}$ observed that complex TiN-MnS precipitates promoted AF primarily by the increased driving en-

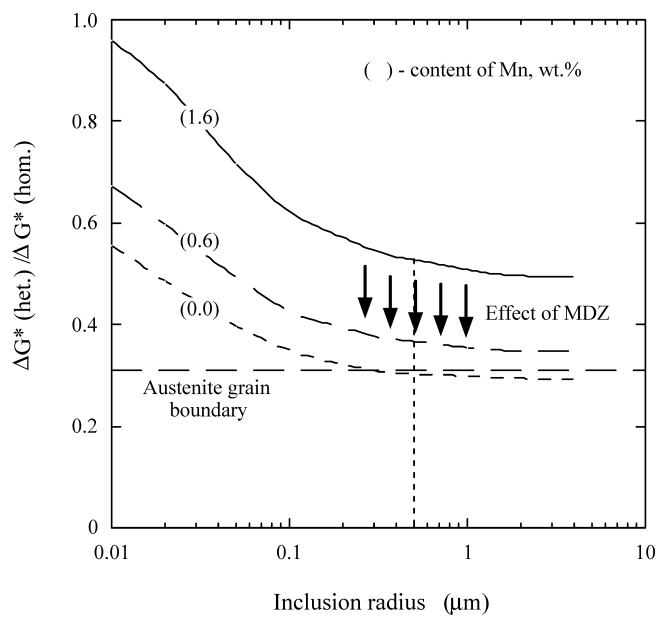

Fig. 13. Activation energy of heterogeneous nucleation of ferrite as a function of inclusion size for a Mn-deplete zone (MDZ) in steels with different Mn contents. ${ }^{64)}$

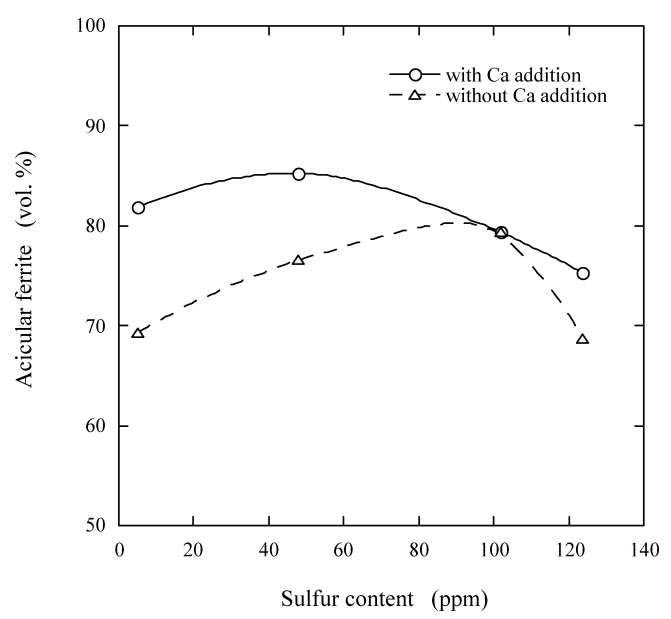

Fig. 14. Effect of sulfur content on volume fraction of intragranular acicular ferrite in Ti-killed steel with and without Ca additions. ${ }^{46)}$

ergy due to a Mn depleted zone. They also agreed that a decrease in interfacial energy due to a crystal coherency of TiN and ferrite has only a complementary role. Yamamoto et $a l .{ }^{61)}$ also confirmed these results.

Another possible mechanism for formation of a Mndepleted zone around the inclusions by $\mathrm{Mn}$ diffusion into $\mathrm{Ti}_{2} \mathrm{O}_{3}$ inclusions is described by Gregg and Bhadeshia. ${ }^{66)}$ In addition, Eijk et al. ${ }^{62)}$ also considered Mn depleted zones surrounding Mn titanates in a Ti-bearing low-carbon steel to be responsible for nucleation of AF. Also, Byun et al. ${ }^{64)}$ found that $\mathrm{Ti}_{2} \mathrm{O}_{3}$ inclusions in a Ti-bearing low-alloy steel had Mn-depleted zones around them, facilitating intragranular nucleation of ferrite. This was also confirmed by Shim et al. ${ }^{63)}$ Also, while reviewing the mechanisms of AF nucleation in weld metals and HAZ, Koseki ${ }^{12)}$ concluded that manganese depletion works in HAZ, while lattice matching is preferred in weld metals.

\section{Effect of Non-metallic Inclusions on Nucleation of Acicular Ferrite}

Though an inclusion provides the external surface needed for nucleation, it is not as effective as a grain 
boundary. This is due to the fact that the free energy for nucleation of ferrite at the inclusion surface is generally higher than that at a high-angle grain boundary, as shown by the data reported by Ricks et al. $^{49)}$ in Fig. 8. However, the free energy for heterogeneous nucleation at an inclusion is much lower than that for homogeneous nucleation of ferrite and is slightly lower than that for a small angle boundary.

\subsection{Size of Inclusions}

Before we discuss which inclusions are active in nucleating acicular ferrite, it can be said that there is one thing that is common for all inclusions that act as nucleants. That is their size. As mentioned above, the energy barrier to heterogeneous nucleation of ferrite at inclusions decreases significantly with an increased inclusion diameter in the range from 0 to $1 \mu \mathrm{m}$. This is due to the increase of the particle surface area. However, it follows from Fig. 8 that the value of this energy barrier for particles with diameters larger than about $1 \mu \mathrm{m}$ decreases only slightly with a further increase of the inclusion size. It is not necessary to increase the diameter of inclusions larger than $1 \mu \mathrm{m}$ to further increase the possibility of ferrite nucleation on an inclusion surface. Based on these results, it can be assumed that the diameter of inclusion of approximately $1 \mu \mathrm{m}$ is the critical size of particles for heterogeneous nucleation of acicular ferrite.

Some authors ${ }^{44,52,69,70)}$ have tried to experimentally estimate the effective inclusion size for heterogeneous nucleation of acicular ferrite. More specifically, Barbado et al. ${ }^{69)}$ stated that an inclusion of $\sim 0.4 \mu \mathrm{m}$ size was very effective in nucleating AF. Furthermore, Krauklis et al. ${ }^{44)}$ found that the size range of effective inclusions in two low-carbon steel grades was found to be $0.4-0.8 \mu \mathrm{m}$. Also, Lee ${ }^{70)}$ has found that inclusions of a $0.25-0.8 \mu \mathrm{m}$ diameter have a good nucleation potential. Subsequently Lee et al. ${ }^{52)}$ reported that the probability of ferrite nucleation on an inclusion surface increases with its size till about $1 \mu \mathrm{m}$, as shown in Fig. 15. Note, that the probability for nucleation of an acicular ferrite lath on an inclusion surface at a given size range, $d_{i}$, was estimated by dividing the number of inclusions, which were determined as ferrite nucleants, by the total number of inclusions in this size range. It is apparent

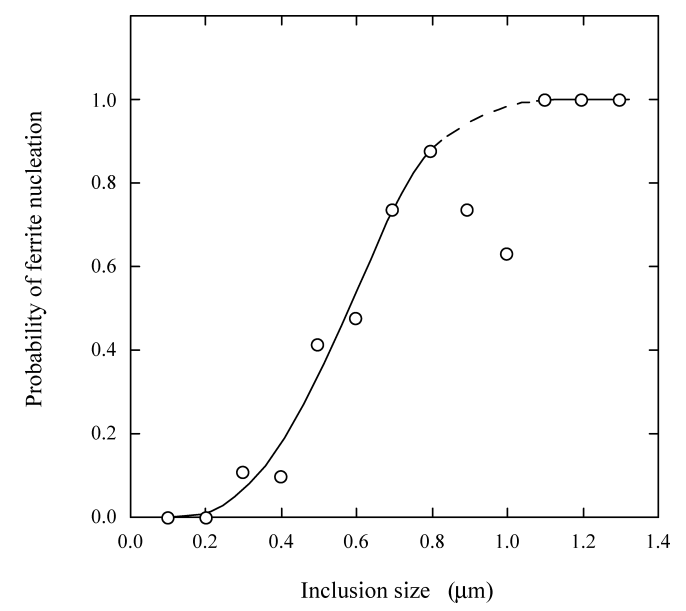

Fig. 15. Effect of inclusion size on the probability of ferrite nucleation. $^{52)}$ from Fig. 15 that the probability of AF nucleation increases rapidly with an increased inclusion diameter in the range from 0.4 to $0.8 \mu \mathrm{m}$ and reaches a value of 1.0 at a diameter of about $1.1 \mu \mathrm{m}$. On further increasing the size of inclusions, the probability of AF nucleation practically does not change. These experimental results correspond very well with findings obtained by Ricks et al. ${ }^{49)}$ as shown in Fig. 8.

Grong et al. $^{71)}$ refers to the inclusions (such as oxides, sulphides, carbides or nitrides) of $\sim 1 \mu \mathrm{m}$ size, which are capable of promoting the nucleation of AF, as "dispersoids". This is especially because they are not harmful to mechanical properties because of their small size. This can be one good way of differ these "smaller" and active inclusions from the more traditional inclusions, which mostly have negative effects on the material properties.

\subsection{Number of Inclusions}

Another important characteristic to obtain a fine microstructure with a high volume fraction of acicular ferrite is the number of inclusions which serve as ferrite nucleants in steel. Here, Kim et al. ${ }^{72)}$ reported that acicular ferrite was in proportion to the number density of inclusions which are smaller than $2 \mu \mathrm{m}$. Also, Zhang and Farrar ${ }^{51)}$ stated that the number and size distribution of the inclusions was a dominant factor. In addition, Guo et $a l^{73)}$ found that electromagnetic stirring of a weld increased the density of fine inclusions $(0.2-0.6 \mu \mathrm{m}$ diameter) and this increased the amount of acicular ferrite in the microstructure. Furthermore, Oh et $a l{ }^{74)}$ reported that the volume fraction of inclusions is more effective in forming AF than their type or size distribution.

Lee et al. ${ }^{52)}$ studied the acicular ferrite nucleation on inclusions in low-carbon steel welds based on TEM investigations. All inclusions were regarded as either non-nucleants (types 1 and 2) or nucleants (types 3 and 4) for ferrite. The total size distribution of all inclusions and inclusion-nucleants for acicular ferrite are shown in Fig. 16. The total size distribution of all particles was obtained as a sum of all inclusion types observed by Lee et al. ${ }^{52)}$ The number of AF nucleants for each step of inclusion size, $d_{i}$, was calculated as the product of the inclusion number, $n_{i}$, and the probability of acicular ferrite nucleation, $P_{i}$, obtained from Fig. 15. Though the inclusions with a diameter larger than $1 \mu \mathrm{m}$ have a larger probability for ferrite nucleation, the largest

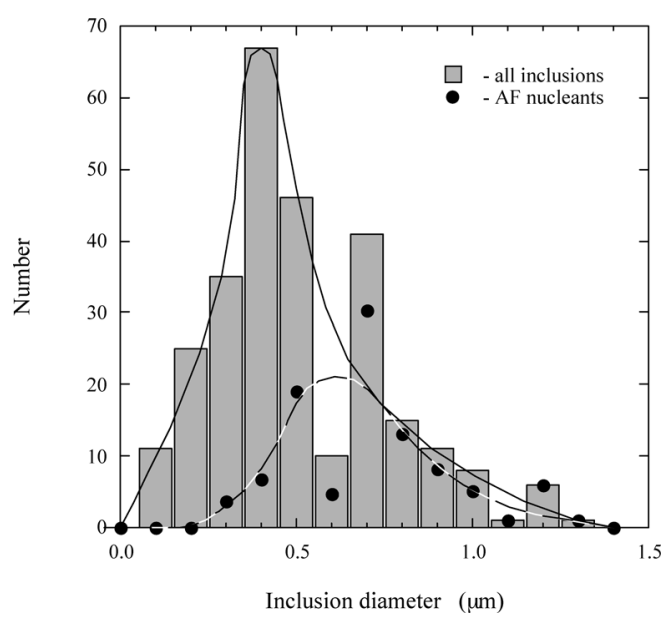

Fig. 16. Size distribution of all inclusions and inclusions as nucleants for acicular ferrite in low-carbon steel welds. 
numbers of AF nucleants have diameters in the range from 0.5 to $0.8 \mu \mathrm{m}$, as shown in Fig. 16. Therefore, the inclusions with sizes from 0.5 to $0.8 \mu \mathrm{m}$ have a large influence on the formation of microstructure with a high ratio of acicular ferrite. However, the probability of AF nucleation on these inclusions is considerable smaller than that for inclusions with a diameter larger than $1 \mu \mathrm{m}$. In addition, it should be pointed out that only $36 \%$ of the inclusions in the weld, which are classified as type $3(26 \%)$ and type 4 $(10 \%)$, are acting as AF nucleants. Despite these facts, they are able to form a weld microstructure with over $80 \%$ of acicular ferrite. In additional, Lee et al. ${ }^{52)}$ did not find a significant difference in results with respect to inclusion composition. However, the different behavior of inclusions with various sizes as AF nucleants may, for example, be dependent on the different precipitation ratio of $\mathrm{MnS}$ inclusions.

\subsection{Composition of Inclusions}

Based on chemistry, the inclusions may be classified as oxides (like simple oxides $\mathrm{SiO}_{2}, \mathrm{Al}_{2} \mathrm{O}_{3}, \mathrm{Ti}_{2} \mathrm{O}_{3}, \mathrm{MnO}$ and complex oxides $\mathrm{MnO}-\mathrm{SiO}_{2}, \mathrm{CaO}-\mathrm{Al}_{2} \mathrm{O}_{3}$ ), nitrides (like TiN, BN, VN), sulphides (like MnS, CaS) and complex inclusions (like oxy-sulphides of cerium, $\mathrm{Al}_{2} \mathrm{O}_{3}-\mathrm{MnS}$ and multi-phase inclusions $\left.\mathrm{MnS}-\mathrm{TiN}-\mathrm{CeO}_{2}-\mathrm{CeS}\right)$. Moreover, all inclusions can be classified as active or inert depending on their potential to intragranularly nucleate acicular ferrite. An influence of chemical composition of inclusions on $\mathrm{AF}$ formation is determined in most cases by the factors such as i) the lattice mismatch strain between the inclusions and matrix metal, ii) thermal strains at the inclusions, and iii) a Mn-depleted zone near MnS inclusions, which are described in Sec. 4. Some of the most often employed inclusions for control of microstructure are discussed in this Section.

\subsubsection{Oxides}

Among different steel deoxidants, $\mathrm{Al}$ is the most common alloying element added for complete killing of the steel. Therefore, the simple $\mathrm{Al}_{2} \mathrm{O}_{3}$ oxides or complex inclusions, which contain some amount of $\mathrm{Al}_{2} \mathrm{O}_{3}$, are commonly observed in different steel grades. The oxide $\mathrm{Al}_{2} \mathrm{O}_{3}$ by itself, is generally not considered to be an effective nucleant for AF. Moreover, it is considered that dissolved Al promotes the formation of GB ferrite. However, the manganese-aluminate such as galaxite spinel $\mathrm{MnO} * \mathrm{Al}_{2} \mathrm{O}_{3}{ }^{48)}$ is preferred for nucleation of acicular ferrite.

It is now well established that various Ti-oxides are very potent nuclei for the formation of $\mathrm{AF}^{6,63,64,69,75-79)}$ More specifically, Mills et al. ${ }^{75)}$ found that TiO could nucleate AF due to it has a low misfit with $\alpha$ and also because of its simple orientation relationship. Also, Babu et al ${ }^{76)}$ showed that titanium-rich inclusions accelerated kinetics of AF formation in the weld metal. While studying the role of inclusions on the development of inoculated steels on AF formation, Barbaro et al. ${ }^{69)}$ found that inclusions containing Ti and $\mathrm{O}$ were very effective in plate steels. According to Shim et al., ${ }^{63)} \mathrm{Ti}_{2} \mathrm{O}_{3}$ particles were inert in a $\mathrm{Mn}$-free steel, but they were effective in a Mn-bearing steel. Furthermore, the $(\mathrm{Ti}, \mathrm{Mn})_{2} \mathrm{O}_{3}$ particles formed in the latter steel absorbed $\mathrm{Mn}$ atoms from the surrounding steel matrix to form AF. Also, Byun et al. ${ }^{64)}$ found the formation of $\mathrm{AF}$ in a $\mathrm{C}-\mathrm{Mn}$ steel killed only with titanium $(\mathrm{Al}<0.0005 \%)$, when the $\mathrm{Ti}$ content was more than $50 \mathrm{ppm}$. This was attributed to a change in the inclusion composition from a $\mathrm{Mn}-\mathrm{Si}$ oxide (at nearly $0 \% \mathrm{Ti}$ ) to a $\mathrm{MnTiO}_{2}$ inclusion (up to $\sim 0.0045 \%$ $\mathrm{Ti}$ ) and finally to a $\mathrm{Ti}_{2} \mathrm{O}_{3}$ inclusion (at $0.011 \% \mathrm{Ti}$ ). Also, Cho et al ${ }^{78)}$ found that when $\mathrm{Ti}$ is added to wrought $\mathrm{C}-\mathrm{Mn}$ steel grades, the microstructure changed to AF that nucleated on $\mathrm{Ti}_{2} \mathrm{O}_{3}$ inclusions. According to the reported results, it is apparent that the conditions by complex deoxidation of steels with $\mathrm{Ti}$ and other deoxidants should be made favourable for Ti-oxides to act as nucleation sites for acicular ferrite.

Some of the complex oxides resulting from complex deoxidation of steels can also nucleate acicular ferrite. As has already been stated, galaxite inclusions, which can form in steels containing $\mathrm{Mn}$ and which have been deoxidized by $\mathrm{Al}$, are more potent than alumina for nucleation of acicular ferrite. More specifically, the inclusions that will nucleate AF are aluminium-manganese silicates. Their effectiveness was explained by the highest thermal expansion difference from iron in comparison with all other inclusions, as follows from Fig. 10. Also, $\mathrm{He}$ and Edmonds ${ }^{80}$ ) found that $\mathrm{Si}-\mathrm{Mn}$ oxide inclusions formed in $\mathrm{C}-\mathrm{Mn}-0.2 \% \mathrm{~V}$ steels, containing $0.015 \%$ oxygen, were effective in nucleating acicular ferrite plates.

It is clear that not all complex oxide inclusions have a positive effect on the nucleation of acicular ferrite. For example, calcium-aluminate and $\mathrm{CaO}-\mathrm{Al}_{2} \mathrm{O}_{3}-\mathrm{SiO}_{2}$ inclusions, which can form due to the modification of alumina inclusions by $\mathrm{Ca}$ addition, do not favour the formation of $\mathrm{AF}$. Similarly, $\mathrm{Mg}$ from refractories or fluxes can form $\mathrm{MgO}-$ $\mathrm{Al}_{2} \mathrm{O}_{3}$ (spinel type). However, Park and $\mathrm{Kim}^{81)}$ showed that these spinels also do not nucleate AF.

\subsubsection{Nitrides}

Pure TiN inclusions can also act as potential nucleation sites for AF formation due to its coherency with ferrite, ${ }^{55-57)}$ as was described in Sec. 4.2. However, other authors ${ }^{11,63,66)}$ have reported a contradictory opinion regarding the effectiveness of TiN. For example, Bhadeshia ${ }^{11)}$ and Shim et al. ${ }^{63)}$ stated that TiN was ineffective for AF nucleation.

In the case of vanadium additions, $\mathrm{He}$ and Edmonds ${ }^{80)}$ showed that the formed acicular ferrite in $\mathrm{C}-\mathrm{Mn}-0-2 \% \mathrm{~V}$ steels did not originate from $\mathrm{VN}$ inclusions. Also, Hajeri et $a l{ }^{82)}$ stated that the $\mathrm{VN}$ inclusions are not active nucleants for $\mathrm{AF}$ formation in thick plates of wrought A572 grade vanadium-steel containing $0.08 \% \mathrm{C}-1.4 \% \mathrm{Mn}$ and $0.13 \% \mathrm{~V}$.

\subsubsection{Sulfides}

The most common sulfide in steels is MnS. These pure $\mathrm{MnS}$ inclusions are not active nucleants for acicular ferrite, because they are incoherent in austenite. ${ }^{53)}$ Moreover, they also have the least difference in thermal expansion coefficient from austenite, as shown in Fig. 10. Thus, they cannot be effective nuclei for AF formation. However, as stated earlier, the formation of a Mn-depleted zone near MnS inclusions, which newly precipitated on oxide inclusions, promotes the nucleation of acicular ferrite. This point will be discussed below dealing with complex inclusions. 


\subsubsection{Complex Oxy-sulfides and Multi-phase Inclusions}

The most common inclusions, which often are stated as nucleants for acicular ferrite in steel, are oxy-sulfides and complex multi-phase inclusions. It can be explained by the simultaneous action of different factors for an effective AF nucleation. More specifically, they can be i) a low mismatch strain between the inclusions and ferrite, ii) positive thermal strains in the surrounding matrix due to the high difference in thermal expansion coefficients for inclusion and matrix, and iii) formation of a Mn-depleted zone in the matrix adjacent to the MnS inclusion. Therefore, the complex inclusions are more active nucleants for acicular ferrite in comparison with simple oxides, nitrides and sulfides.

Lee and $\mathrm{Pan}^{46}$ found that $\mathrm{Ti}$ and Ti-Ca oxy-sulfides in Ti-killed steels effectively promoted the formation of AF. Moreover, the Ti oxy-sulfides possessed better nucleation potential than simple Ti-oxides and $\mathrm{MnS}$. As a result, the best HAZ toughness was obtained in Ti-killed steel grades at sulfur contents of about $100 \mathrm{ppm}$, when Ti oxides get converted to Ti and Ti-Ca oxy-sulfides.

There is voluminous literature to show that the complex inclusions of many steels contain various components like oxides, sulfides and nitrides. In 1983, Kayali et al. ${ }^{83)}$ were probably among the first to report that the central core of the inclusion had a different composition than the surrounding surface. Also, Court and Pollard ${ }^{84)}$ observed complex inclusions in steel welds of both categories. More specifically, $(\mathrm{Mn}, \mathrm{Ti})$-silicates and $(\mathrm{Mn}, \mathrm{Cu}) \mathrm{S}$ nucleated $\mathrm{AF}$ and $\left(\mathrm{FeO}, \mathrm{SiO}_{2}\right)$ that did not nucleate AF. In addition, Mills et $a l{ }^{75)}$ found that the surface of inclusions could contain a variety of phases like $\mathrm{TiO}$ or TiN together with $\mathrm{MnS}$ and $\mathrm{Cu}_{2} \mathrm{~S}$, while their core comprised of galaxite. Expectedly, they reported that the nucleation of AF was independent of the underlying bulk composition of the inclusion. Also, Grong et al. ${ }^{50)}$ found that the chemical composition of the core formed in the primary deoxidation stage could vary widely depending on the activities of $\mathrm{Al}, \mathrm{Ti}, \mathrm{Si}, \mathrm{Mn}$ and $\mathrm{O}$ in the weld metal. Their surfaces were covered with $\mathrm{MnS}$ and TiN by solute-enrichment in the inter-dendritic liquid during the solidification stage. In addition, St-Laurent and Esperance $^{85)}$ found that a small Ti content (39 ppm) in the weld metal was enough to form a titanium-rich phase. That phase partially covered the inclusions. The efficiency of the nucleation was related to the total external surface area of the titanium-rich phase per unit area of weld metal. Also, Tomita et al. ${ }^{86)}$ stated that most of the TiN-MnS complex precipitates effectively promoted AF over a wide range of heat inputs in high-strength steel grades for offshore structures.

Thewlis ${ }^{48)}$ found that while only galaxite inclusions were formed in low B-Ti steel welds, TiO/TiN formed at the surface layers of these inclusions in high B-Ti steels that nucleated AF. Also, Mabuchi et al. ${ }^{60)}$ found that all the following phases $\mathrm{Ti}_{2} \mathrm{O}_{3}$, TiN and MnS could exist in the same inclusion for effective nucleation of acicular ferrite. In addition, Yamamoto et al. ${ }^{61)}$ reported that the precipitation of $\mathrm{MnS}$ and TiN on the already existing $\mathrm{Ti}_{2} \mathrm{O}_{3}$ inclusions acted as preferential nucleation sites for AF. Furthermore, Shim and co-workers ${ }^{63,64,79)}$ reported that $\mathrm{Ti}_{2} \mathrm{O}_{3}$ particles were inert in a Mn-free steel. However, they were active in a Mn- containing steel $(0.2 \% \mathrm{C}, 1.5 \% \mathrm{Mn} / 2.5 \% \mathrm{Ni}$, with small amounts of Ti, V, N, S and O). The nucleation of AF in the last case was explained by the formation of $(\mathrm{Ti}, \mathrm{Mn})_{2} \mathrm{O}_{3}$ particles and the presence of a Mn-depleted zone, due to the absorption of $\mathrm{Mn}$ atoms from the surrounding steel matrix. They also found that $\mathrm{MnS}$ and $\mathrm{Al}_{2} \mathrm{O}_{3}$ particles in a $\mathrm{V}-\mathrm{N}$ steel could nucleate AF because $\mathrm{MnS}$ was coexisting with VN.

Miyamoto et al. ${ }^{87)}$ and Furuhura et al. ${ }^{53,54)}$ observed that the addition of about $0.3 \% \mathrm{~V}$ and $0.01 \% \mathrm{~N}$ to a low-carbon steel makes it more effective in nucleating AF. This was due to the formation of MnS-V(C,N) complex precipitates. Here, the role of $\mathrm{N}$ was to increase the volume fraction of $\mathrm{V}(\mathrm{C}, \mathrm{N})$ inclusions. Working on a Ti-containing low carbon steel, Jin et al $^{57)}$ found that TiN formed from complex inclusions $\left(\mathrm{Ti}_{2} \mathrm{O}_{3}-\mathrm{TiN}, \mathrm{TiN}-\mathrm{MnS}\right)$ was an effective nucleant for AF.

Recently Grong and co-workers (Eijk et al.) ${ }^{50,62,71,88)}$ showed experimentally that the inclusions had not only a complex distribution of phases, but also a non-uniform distribution of elements within the inclusion. It was found that inclusions in hot-rolled steels deoxidized with Ti were complex Ti- and Al-oxides with MnS and TiN which had been precipitated on the surface. These complex inclusions were active for AF nucleation. In addition, they found that neither $\mathrm{MnS}$ nor $\mathrm{Ce}-\mathrm{O}-\mathrm{S}$ inclusions in a $037 \mathrm{X}$ line pipe $(0.1 \% \mathrm{C}-1 \% \mathrm{Mn})$ steel with an addition of $0.02-0.04 \% \mathrm{Ce}$ and of $0.007-0.009 \% \mathrm{Al}$ could nucleate AF by themselves. However, the patches of $\mathrm{MnS}$, which formed around $\mathrm{Ce}-$ $\mathrm{O}-\mathrm{S}$ complex inclusion, promoted AF nucleation. ${ }^{71,88)}$ In addition, according to Grong et al.,$^{71)}$ the range of composition in Ce-alloyed steels is very narrow in obtaining active inclusions.

As mentioned in the introduction of Sec. 5.3, all inclusions can be classified as active or inert depending on the potential to nucleate acicular ferrite. In Table 2, the active and inert inclusions discussed in this paper are summarized. As can be seen, the majority of the inclusions that were found to serve as active inclusions for AF formations were complex and multi-phase inclusions. Thus, in order to introduce these under production conditions, it is necessary to obtain good control of inclusion compositions during the processing of steel.

\subsection{Inclusion Metallurgy}

In order to produce a steel with a controlled acicular ferrite structure it is also necessary to consider the steel making and casting process. Thus, in 1990, Takamura and Mizoguchi $^{90)}$ introduced Oxide Metallurgy as a means of using suitable non-metallic inclusions as heterogeneous nucleation sites during solidification. Later in 1995 , Wijk ${ }^{91)}$ promoted Inclusion Engineering to develop knowledge on how to control the amount, size distribution and composition of inclusions in steel during both ladle refining and casting. According to him, this was necessary to better optimize material properties which are highly influenced by the presence of inclusions. Almost a decade later in 2006 Grong et $a l{ }^{71)}$ combined these two ideas. He suggested that one has to practice Inclusion Engineering to get the optimum microstructure for optimum mechanical properties. This was based on their findings that a strict control of chemical 
Table 2. Influence of chemical composition of inclusions on their potential to intragranular nucleation of acicular ferrite.

\begin{tabular}{|c|c|c|}
\hline $\begin{array}{c}\text { Compound } \\
\text { added }\end{array}$ & $\begin{array}{l}\text { Active inclusions for } \mathrm{AF} \\
\text { nucleation }\end{array}$ & $\begin{array}{c}\text { Inert inclusions for } \mathrm{AF} \\
\text { nucleation }\end{array}$ \\
\hline Simple oxides & Ti-oxides ${ }^{64,66,69,75,76,78)}$ & $\mathrm{Al}_{2} \mathrm{O}_{3}{ }^{63,66)}$ \\
\hline \multirow{7}{*}{$\begin{array}{c}\text { Complex } \\
\text { oxides }\end{array}$} & $\left(\mathrm{Ti}_{2} \mathrm{O}_{3}\right.$ and $\left.\mathrm{TiO}\right)$ & $\mathrm{SiO}_{2}{ }^{63,65)}$ \\
\hline & $\mathrm{TiO}_{2}{ }^{89)}$ & $\mathrm{Ti}_{2} \mathrm{O}_{3}{ }^{63)}$ (in Mn-free steel) \\
\hline & $(\mathrm{Ti}, \mathrm{Mn})_{2} \mathrm{O}_{3}{ }^{63)}$ & $\mathrm{MnO}-\mathrm{SiO}_{2}{ }^{63,64)}$ \\
\hline & (in Mn-bearing steel) & $\mathrm{MnO}-\mathrm{FeO}_{\mathrm{x}}-\mathrm{SiO}_{2}{ }^{65)}$ \\
\hline & $\mathrm{TiO}_{2}-\left(\mathrm{MnO}-\mathrm{Al}_{2} \mathrm{O}_{3}\right)$ & $\mathrm{MgO}-\mathrm{Al}_{2} \mathrm{O}_{3}{ }^{81)}$ \\
\hline & Galaxite spinel ${ }^{48)}$ & \\
\hline & $\mathrm{MnO}-\mathrm{Al}_{2} \mathrm{O}_{3}$ & $\mathrm{MnO}-\mathrm{Al}_{2} \mathrm{O}_{3}{ }^{66)}$ \\
\hline \multirow[t]{2}{*}{ Simple nitrides } & $\operatorname{TiN}^{56,57)}$ & $\operatorname{TiN}^{63,66)}$ \\
\hline & $\mathrm{VN}^{56)}$ & \\
\hline \multirow[t]{2}{*}{ Simple sulfides } & & $\mathrm{MnS}^{53,54,63,66)}$ \\
\hline & & $\mathrm{CuS}^{65)}$ \\
\hline Complex & $\mathrm{Al}_{2} \mathrm{O}_{3}-\mathrm{MnS}^{23)}$ & \\
\hline oxy-sulfides & $\mathrm{Ti}_{2} \mathrm{O}_{3}-\mathrm{Al}_{2} \mathrm{O}_{3}-\mathrm{MnS}^{23)}$ & \\
\hline and & Ti- and Ti-Ca-oxy-sulfides ${ }^{46)}$ & \\
\hline multi-phase & $\mathrm{Ti}_{2} \mathrm{O}_{3}-\mathrm{TiN}-\mathrm{MnS}^{57)}$ & \\
\hline \multirow[t]{4}{*}{ inclusions } & $\mathrm{TiO}_{\mathrm{x}}-\mathrm{TiN}-\mathrm{MnS}{ }^{17)}$ & \\
\hline & $\begin{array}{l}\text { FeS-(Mn, } \mathrm{Cu}) \mathrm{S}^{65} \text { ) } \\
\text { (in low carbon steel without spetial }\end{array}$ & \\
\hline & alloying elements) & \\
\hline & MnS-VC, MnS-V(C,N $)^{53,54)}$ & \\
\hline
\end{tabular}

composition of steel is required to produce the inclusions with adjusted composition and structure, which is a basic necessity to produce an AF structure. Furthermore, they suggested that it is necessary to first make clean steel with respect to inclusions and then to add active inclusions ("dispersoids") separately to the melt to obtain AF structures confidently. With respect to this subject, for example Andersson et al. ${ }^{92)}$ have discussed the metallurgical challenges of providing a homogenous distribution of inclusions suitable for grain reefing into steel at the onset of solidification. This is, of course, of outmost importance in order to be able to obtain the benefits of grain refining under production conditions. However, a deeper discussion on this control of potential inclusions, suitable for the formation of acicular ferrite, during ladle refining and casting is out of the scope of the current paper.

\section{Conclusion}

It is universally agreed that the steels with a high volume fraction of acicular ferrite in the microstructure have an excellent combination of strength and toughness. For promoting the formation of acicular ferrite structures, it is necessary to get the optimum chemical composition of steel. This, in turn, is obtained by controlled alloying (with Mn, $\mathrm{Ni}$, and $\mathrm{Mo}$ ) and adequate additions of microalloying or impurity elements ( $\mathrm{V}, \mathrm{Ti}, \mathrm{Al}, \mathrm{Nb}, \mathrm{Ce}, \mathrm{B}, \mathrm{O}, \mathrm{S}$ and $\mathrm{N})$. Moreover, the cooling rate of the steel from the austenitic state and the size of austenite grains also highly influences the microstructure obtained in the weld metal and the heataffected zone of steel.

A presence of certain inclusions in steel is necessary as possible sites for heterogeneous nucleation of intragranular acicular ferrite. The large size inclusions with $d_{\mathrm{V}}>1 \mu \mathrm{m}$ have a larger probability for ferrite nucleation. However, most of the AF nucleants in steel have diameters in the range from 0.5 to $0.8 \mu \mathrm{m}$. Though the number of inclusions in steel is considered as a principal factor in the nucleation of acicular ferrite, it is only about $10-36 \%$ of the inclusions that take part in the process of nucleation. A vast majority of inclusions have therefore no role in the nucleation of ferrite.

It follows from these results that both the composition and the structure of inclusions are the deciding factors for intragranular nucleation of acicular ferrite. It is generally agreed that single-phase inclusions like simple oxide $\left(\mathrm{Al}_{2} \mathrm{O}_{3}, \mathrm{MnO}\right.$ and $\left.\mathrm{SiO}_{2}\right)$ and sulfide $(\mathrm{MnS})$ can not nucleate acicular ferrite. However, titanium oxides as well as nitrides of vanadium and titanium, certain $\mathrm{Mn}$ silicates and Ce sulfides are considered to be effective for AF nucleation.

The complex inclusions (oxy-sulfides and multi-phases inclusions) are more active nucleants for acicular ferrite in comparison with simple oxides such as nitrides and sulfides. This can be explained by the possible joint action of different factors for effective AF nucleation: i) a low mismatch strain between the inclusion and ferrite, ii) a positive thermal strain in the surrounding matrix due to the high difference in the thermal expansion coefficient between the inclusion and the matrix, iii) a minimization of the interfacial energy and iv) formation of a Mn-depleted zone in the matrix adjacent to the $\mathrm{MnS}$ inclusion.

There is considerable experimental evidence to show that inclusions in commercial steel grades and their welds consist of two or more phases. Furthermore, that their composition varies from the center to the surface of the inclusion. The numerous investigations performed by using scanning and transmission electron microscopy techniques have shown that inclusions in steels are very complex with different components in the core and at the surface. The core could be an oxide, while the surface has patches of some sulfides or oxy-sulfides and/or nitrides. Once the core of the inclusion is formed in the primary solidification stage, other components of the inclusion like nitrides (like VN, TiN) and sulfides of $\mathrm{Mn}, \mathrm{Cu}$ and $\mathrm{Ce}$ can get deposited on their surface by solute enrichment in the interdendritic liquid during the solidification stage.

The development of steels using fine particles of inclusions as "dispersoids" to achieve acicular ferrite structures with good mechanical properties by carefully controlling the steel making procedures can open interesting areas in the field of "Inclusion Engineering".

\section{Acknowledgements}

The authors wish to thank the Brinel Centre for the financial support to carry out this research. Furthermore, the Kami Research Foundation for the financial support to A. Karasev for his participation in writing this publication.

\section{REFERENCES}

1) R. Kiessling: Clean Steel, Metals Society, London, (1983), 1.

2) R. Lagneborg: Uddeholm Symp. on Inclusions in Steel, Södertalje, Ramström, Sunne, (1981), 285.

3) F. B. Pickering: Mechanical Working and Steel Processing Prooceedings, Iron and Steel Society, Warrendale, PA, (1989), 381. 
4) T. Gladman: Ironmaking Steelmaking, 19 (1992), 467.

5) The Making, Shaping and Treating of Steel, 10th ed., ed. by W. T. Lankfore, Jr. et al., USS, (1985), 495.

6) O. Grong and D. K. Matlock: Int. Met. Rev, 31 (1986), 27.

7) D. J. Abson and P. J. Pargeter: Int. Met. Rev., 31 (1986), 141

8) R. A. Farrar and P. L. Harrison: J. Mater. Sci., 22 (1987), 3812.

9) H. K. D. H. Bhadeshia and L. E. Svensson: Mathematical Modelling of Weld Phenomena, ed. by H. Cerjak and K. E. Eastering, Inst. of Mater., London, (1993), 109.

10) S. Ohkita and Y. Horii: ISIJ Int., 35 (1995), 1170.

11) H. K. D. H. Bhadeshia: Bainite in Steels, 2nd ed., Inst. of Metals, London, (2001), 276.

12) T. Koseki: Weld. World, 49 (2005), 22

13) T. Koseki and G. Thewlis: Mater. Sci. Technol., 21 (2005), 867.

14) J. D. Verhoeven: Fundamentals of Physical Metallurgy, John Wiley \& Sons, New York, (1975), 425.

15) A. K. Sinha: Ferrous Physical Metallurgy, Butterworths, Boston, (1989), 205.

16) Metals Handbook, 9th ed., Vol. 9, ASM, Materilas Park, OH, (1985), 656.

17) C. van der Eijk, O. Grong and J. Hjelen: Proc. of Int. Conf. on SolidSolid Phase Transformations, JIM, Sendai, (1999), 1.

18) R. A. Farrar and P. L. Harrison: J. Mater. Sci., 16 (1981), 2218

$19)$ R. A. Farrar and P. L. Harrison: J. Mater. Sci., 28 (1993), 1385.

20) M. Strangwood and K. Chi: Proc. of Int. Conf. on Solid-Solid Phase Transformations in Inorganic Materials, TMS, Warrendale, PA, (2005), 93.

21) G. Thewlis: Mater. Sci. Technol., 22 (2006), 153.

22) T. Pan, Z.-G. Yang, C. Zhang, B.-Z. Bai and H.-S. Fang: Mater. Sci Eng. A, 438-440 (2006), 1128.

23) Z. Yang, F. Wang, S. Wang and B. Song: Steel Res. Int., 79 (2008), 390.

24) J. G. Garland and P. R. Kirkwood: Metal Constr., 7 (1975), 275

25) J. G. Garland and P. R. Kirkwood: Metal Constr., 7 (1975), 320.

26) Y. Peng, W. Chen and Z. Xu: Mater. Charact., 47 (2001), 67.

27) D. Fairchild, M. Macia, N. Bangaru, J. Koo, A. Ozekcin and H. Jin: Proc. of 7th Int.Conf. on Trends in Welding Research, ASM, Materials Park, OH, (2005), 749.

$28)$ D. P. Fairchild, M. L. Macia, N. V. Bangaru and J. Y. Koo: Proc. of 13th Int. Offshore and Polar Eng. Conf., Honolulu, USA, (2003), 2276 .

29) A. Takahashi, T. Hara, H. Ogawa, H. Tamehiro and H. Ishikawa: CAMP-ISIJ, 6 (1994), 644.

30) N. Christensen and T. Simonsen: Scand. J. Metall., 10 (1981), 147.

31) C. R. Simcoe, A. R. Elsea and G. M. Manning: Trans. AIME, 203 (1955), 193.

32) D. A. Mortimer and M.G. Nicholas: Met. Sci., 10 (1976), 326

33) G. Den Ouden, J. G. Verhagen and G. W. Tichelaar: Weld J. Res. Suppl., 54 (1975), 87s.

34) G. M. Evans: Weld J. Res. Suppl., 62 (1983), 313s.

35) G. M. Evans: Weld. J., 59 (1980), 67s.

36) S. S. Tuliani, T. Boniszewski and N. F. Eaton: Weld. Met. Fabr, 37 (1969), 327.

37) W. Bose-Filho, A. L. M. Carvalho and M. Strangwood: Mater. Charact., 58 (2007), 29.

38) A. G. Glover, J. T. McGrath, M. J. Tinkler and G. C. Weatherly: Weld. J., 56 (1977), 267s

39) R. E. Dolby: Met. Technol., 10 (1983), 349.

40) I. Madariaga, I. Gutierrez and C. Garcia-de Andres: Scr. Mater., 41 (1999), 229.

41) J. H. Shim, Y. W. Cho and S. H. Chung: Acta Mater., 47 (1999), 2751

42) J. S. Byun, J. H. Shim and J. Y. Suh: Mater. Sci. Eng. A, 319-321 (2001), 326.

43) F. Ishikawa, T. Takahashi and T. Ochi: Metall. Mater. Trans. A, 25A (1994), 929.

44) P. Krauklis, F. J. Barbaro and K. E. Easterling: Proc. of Int. Conf. on Martensitic Transformations, Montery Institute for Advanced Studies, Montery, (1992), 439.

45) A. V. Karasev and H. Suito: ISIJ Int., 48 (2008), 658.

46) J. L. Lee and Y. T. Pan: ISIJ Int., 35 (1995), 1027.

47) J. L. Lee: Acta Metall. Mater., 42 (1994), 3291.

48) G. Thewlis: Mater. Sci. Technol., 10 (1994), 110.

49) R. A. Ricks, P. R. Howell and G. S. Barritte: J. Mater. Sci., 17 (1982), 732.

50) O. Grong, A. O. Kluken, H. K. Nylund, A. L. Dons and J. Hjelen Metall. Mater. Trans. A, 26A (1995), 525

51) Z. Zhang and R. A. Farrar: Mater. Sci. Technol., 12 (1996), 237.
52) T. K. Lee, H. J. Kim, B. Y. Kang and S. K. Hwang: ISIJ Int., 40 (2000), 1260

53) T. Furuhara, J. Yamaguchi, N. Sugita, G. Miyamoto and T. Maki: ISIJ Int., 43 (2003), 1630.

54) T. Furuhara, T. Shinyoshi, G. Miyamoto, J. Yamaguchi, N. Sugita, N. Kimura, N. Takemura and T. Maki: ISIJ Int., 43 (2003), 2028.

55) B.L. Bramfitt: Metall. Trans., 1 (1970), 1987.

56) S. Zhang, N. Hattori, M. Enomoto and T. Tarui: ISIJ Int., 36 (1996), 1301

57) H. H. Jin, J. H. Shim, Y. W. Cho and H. C. Lee: ISIJ Int., 43 (2003), 1111.

58) D. Brooksbank and K. W. Andrews: J. Iron Steel Inst., 210 (1972), 246.

59) L. Devillers et al.: Proc. of Int. Conf. on Effect of Residual, Impurity and Microalloying Elements on Weldability and Weld Properties, Welding Inst., London, (1983), Paper 1.

60) H. Mabuchi, R. Uemori and M. Fujioka: ISIJ Int., 36 (1996), 1406.

61) K. Yamamoto, T. Hasegawa and J. Takamura: ISIJ Int., 36 (1996), 80.

62) C. Eijk, O. Grong and J. Walmsley: Mater. Sci. Technol., 16 (2000), 55.

63) J. H. Shim, Y. J. Oh, J. Y. Suh, Y. W. Cho, J. D. Shim, J. S. Byun and D. N. Lee: Acta Mater, 49 (2001), 2115.

64) J. S. Byun, J. H. Shim, Y. W. Cho and D. N. Lee: Acta Mater, 51 (2003), 1593

65) Z. Liu, Y. Kobayashi, F. Yin, M. Kuwabara and K. Nagai: ISIJ Int., 47 (2007), 1781

66) J. M. Gregg and H. K. D. H. Bhadeshia: Acta Mater., 45 (1997), 739

67) The Physical-Chemical Properties of Oxides, Metallurgy, Moscow, (1978), 130.

68) The Thermo-Physical Properties of High Temperatures of Solid Materials, Vol. 4, ed. by Y. S. Touloukian, Macmillan Co., New York, (1967), 462.

69) F. J. Barbaro, P. Krauklis and K. E. Easterling: Mater. Sci. Technol., 5 (1989), 1057

70) J. Lee: Acta Metall. Mater., 42 (1994), 3291.

71) O. Grong, L. Kolbeinsen, C. van der Eijk and G. Tranell: ISIJ Int., 46 (2006), 824

$72)$ B. Kim, S. Uhm, C. Lee, J. Lee and Y. An: Trans. ASME. J. Eng. Mater. Technol., 127 (2005), 204.

73) X. M. Guo, B. N. Qian, Y. Zhang, J. L. Li and P. Zhu: Trans. China Welding Inst., 22 (2001), 27.

74) Y. Oh, S. Lee, J. Byun, J. Shim and Y. Cho: Mater. Trans., JIM, 41 (2000), 1663

75) A. R. Mills, G. Thewlis and J. A. Whitemen: Mater. Sci. Technol., 3 (1987), 1051

76) S. S. Babu, S. A. David and J. M. Vitek: Dept. of Energy, Washington, DC. CONF-950682-11, (1995), 7.

77) H. Goto, K. Miyazawa, W. Yamada and K. Tanaka: ISIJ Int., 35 (1995), 708.

78) Y. Cho, J. Byun and J. Shim: Mater. Sci. Forum, 426-432 (2003), 1511.

79) J. S. Byun, J. H. Shim and Y. W. Cho: Scr. Mater., 48 (2003), 449.

80) K. He and D. V. Edmonds: Mater. Sci Technol., 18 (2002), 289

81) J. Park and D. S. Kim: Metall. Trans. B, 36B (2005), 495.

82) K. Hajeri, C. I. Garcia, M. Hua and A. J. Deardo: ISIJ Int., 46 (2006), 1233

83) E. S. Kayali, J. M. Corbatt and H. W. Kerr: J. Mater. Sci. Lett., 2 (1983), 123.

84) S. G. Court and C. Pollard: J. Mater. Sci. Lett., 4 (1985), 427.

85) S. St-Laurent and G. L. Esperance: Mater. Sci. Eng. A, A149 (1992), 203.

86) N. Tomita, Y. Sato, Y. Tokunaga and K. Okamoto: ISIJ Int., 34 (1994), 829.

87) G. Miyamoto, T. S. Nyoshi, J. Yamaguchi, T. Furuhara, T. Maki and R. Uemori: Scr. Met., 48 (2003), 371.

88) C. Eijk, I. Lasilla, O. Grong, O. S. Klevan and L. Holappa: AIST/TMS Conf. on Materials Science and Technology, TMS, Warrendale, PA, (2004).

89) T. Yamada, H. Terasaki and Y. Komizo: Sci. Technol. Weld. Joining, 13 (2008), 118

90) J. Takamura and S. Mizoguchi: Proc. 6th Int. Iron and Steel Cong., Vol. I, ISIJ, Tokyo, (1990), 591

91) O. Wijk: Proc. Scanmet VII, MEFOS, Luleå, Sweden, (1995), 35.

92) M. Andersson, J. Appelberg, A. Tilliander, K. Nakajima, H. Shibata, S. Kitamura and P. Jönsson: ISIJ Int., 46 (2006), 814. 